\title{
Estimation of biogas produced by the landfill of Palermo, applying a Gaussian model
}

\author{
S. Aronica ${ }^{a}$, A. Bonanno ${ }^{b}$, V. Piazza ${ }^{\text {a }}$, L. Pignato ${ }^{a, *}$, S. Trapani ${ }^{a}$ \\ a Dipartimento di Ricerche Energetiche ed Ambientali (DREAM), Università di Palermo, Viale delle Scienze, Edificio 9, 90128 Palermo, Sicily, Italy \\ ${ }^{\mathrm{b}}$ Istituto per l'Ambiente Marino Costiero, IAMC - CNR, Via L. Vaccara 61, Mazara del Vallo (TP), Italy
}

\section{A R T I C L E I N F O}

\section{Article history:}

Accepted 21 February 2008

Available online 29 April 2008

\begin{abstract}
A B S T R A C T
In this work, a procedure is suggested to assess the rate of biogas emitted by the Bellolampo landfill (Palermo, Italy), starting from the data acquired by two of the stations for monitoring meteorological parameters and polluting gases. The data used refer to the period November 2005-July 2006.

The methane concentration, measured in the CEP suburb of Palermo, has been analysed together with the meteorological data collected by the station situated inside the landfill area. In the present study, the methane has been chosen as a tracer of the atmospheric pollutants produced by the dump. The data used for assessing the biogas emission refer to night time periods characterized by weak wind blowing from the hill toward the city. The methane rate emitted by the Bellolampo dump has been evaluated using a Gaussian model and considering the landfill both as a single point source and as a multiple point one. The comparison of the results shows that for a first approximation it is sufficient to consider the landfill of Palermo as a single point source.

Starting from the monthly percentage composition of the biogas, estimated for the study period, the rate of biogas produced by the dump was evaluated. The total biogas produced by the landfill, obtained as the sum of the emitted component and the recovered one, ranged from 7519.97 to $10,153.7 \mathrm{~m}^{3} / \mathrm{h}$. For the study period the average monthly estimations of biogas emissions into the atmosphere amount to about $60 \%$ of the total biogas produced by the landfill, a little higher than the one estimated by the company responsible for the biogas recovery plant at the landfill.
\end{abstract}

(c) 2008 Elsevier Ltd. All rights reserved.

\section{Introduction}

In the last decades the greenhouse gases produced by human activities have been predominating over those of natural origin (Hansen, 2004). Both the United Nations and the European Union have adopted protocols (e.g., Kyoto protocol) with the purpose of evaluating the emissions of the principal gases responsible for the greenhouse effect, to keep them under control and to reduce their general emissions both in the short-term and long-term periods.

The Kyoto protocol in Europe foresees the reduction of the principal anthropogenic emissions of the gases responsible for altering the natural greenhouse effect. In particular, in the period 20082012 , the industrialized countries should reduce the emissions by $5 \%$ in respect to the 1990 values.

Municipal solid waste (MSW) landfills constitute a broad part of these anthropogenic sources. In fact, the controlled dumps act as biological reactors, in which refuse undergoes physical, chemical and biological phenomena. The progressive stabilization of the refuse is mainly the result of natural biological processes, in which the presence of biotic (bacterial biomass) and abiotic components (micro and macronutrients, toxic or inhibiting compounds, humid-

\footnotetext{
* Corresponding author. Tel.: +39 091 236110; fax: +39 091484425.

E-mail address: angip@unipa.it (L. Pignato).
}

ity, temperature, etc.) play a fundamental role (Viviani and Torregrossa, 1997).

Emitted biogas quantification from dumps is one of the objectives foreseen in the Kyoto protocol; indeed it is important to both evaluate what the contribution of landfills is on the total production and to identify measures that should be adopted for the reduction of these emitted gases. The refuse treatment plants and the recovery during the combustible extraction phases could have economic benefits that may partly cover additional costs of the necessary interventions to reduce biogas levels, such as preventing the escape of biogas in the proximity of the dumps. Nevertheless, the evaluation of biogas emissions from the dumps is not simple, since these are multiple point sources with a high spatial and temporal variability (Scharff et al., 2000).

Some authors have studied the influence of different environmental factors, such as wind and atmospheric pressure, on methane emissions from landfills and their diffusion into the atmosphere (Barbaro et al., in press; Czepiel et al., 2003). Rain also influences the emissions making the dump top-layer less permeable.

Taking into account all of the above, it is not easy to measure the landfill methane emissions and thus different methodologies to estimate the biogas productivity of the landfill are reported in literature (Hensen and Scharff, 2001; Oonk and Boom, 1995; Gregory et al., 2003). Some of these methodologies take into account 
the typology and quantity of refuse in order to estimate the amount of biogas produced vs. time (Scharff and Jacobs, 2006). Other methodologies follow a direct approach, such as the stationary plume measurement (SPM) method which, starting from samples of biogas captured by gas bags when a certain threshold is reached, apply a dispersion model to estimate the concentration variations vs. time (Scharff et al., 2003).

The results of a comparative study are presented in this paper; a pollutant Gaussian dispersion model was applied to Palermo's landfill by considering it both as a single and a multiple point emission source. Such results permitted, by applying the models and by using the methane concentrations measured downwind from the dump, to estimate the total emitted methane by the landfill of Bellolampo.

The application of the mass balance equation and the known percentage composition of the biogas captured in the dump allowed evaluation of the total biogas produced by the dump itself.

\section{The landfill site and the monitoring network}

The municipal waste disposal site of Palermo (Bellolampo landfill) was created in the $1960 \mathrm{~s}$, but only since the 1980 s has it become a controlled dump site. Currently the landfill, located $10 \mathrm{~km}$ from the city centre and at about $450 \mathrm{~m}$ above sea level (Fig. 1), covers an area of about 47 ha. Most of the neighbouring areas are not inhabited and only some are used for pastures. This landfill receives refuse from the city of Palermo and from the environs of about 50 small and medium cities.

A biogas recovery plant, run by the Asja Ambiente Italia S.p.a., was established on the Bellolampo landfill. The company is certified in accordance to the UNI EN ISO 14001 standards and is responsible for the production of green energy through the energy exploitation of the collected biogas produced by the MSW dump. The biogas recovery plant includes about 90 wells, a collector system and an electrical generator. The biogas collected by the intake station is analysed, with the aim of determining its composition, and treated before being sent to a Jenbacher JGC 320 motor for the production of electric energy. The electrical generator is composed of seven generation modules, each one able to produce $1 \mathrm{MW}$.

The biogas fraction not collected by the plant passes through the protection and covering systems of the dump and, subsequently, disperses into the atmosphere. The municipalized company AMIA (Azienda Municipalizzata di Igiene Ambientale), which deals with the disposal of urban solid refuse, has set up a network of 10 stations for monitoring air quality and meteorological parameters in the city of Palermo.

In the present study, we analysed the methane concentrations measured at the "CEP" station, the closest to the landfill area ( $3 \mathrm{~km}$ from the dump), equipped with sensors for the measurement of pollutants. The station is endowed with a gas-chromatograph with FID detector type R526 by PCF Electronica, operating in the $0-10 \mathrm{ppm}$ range. An average hourly methane concentration time series, recorded in the period 7th November 2005-31st July 2006 , was analysed in order to evaluate the occurrence of high level of gas concentration (acute phenomena). For the same period, the analysis of meteorological data (wind speed and direction, solar radiation and cloud cover) collected by the station situated within the landfill area, permitted estimation of percentage frequencies of wind speed and stability class.

Available data on the amount of methane and biogas extracted by the Asja company for the period November 2005-July 2006, together with the percentages of methane and carbon dioxide estimated by the same company on the extracted biogas, were used to evaluate total biogas and methane production for the Bello-

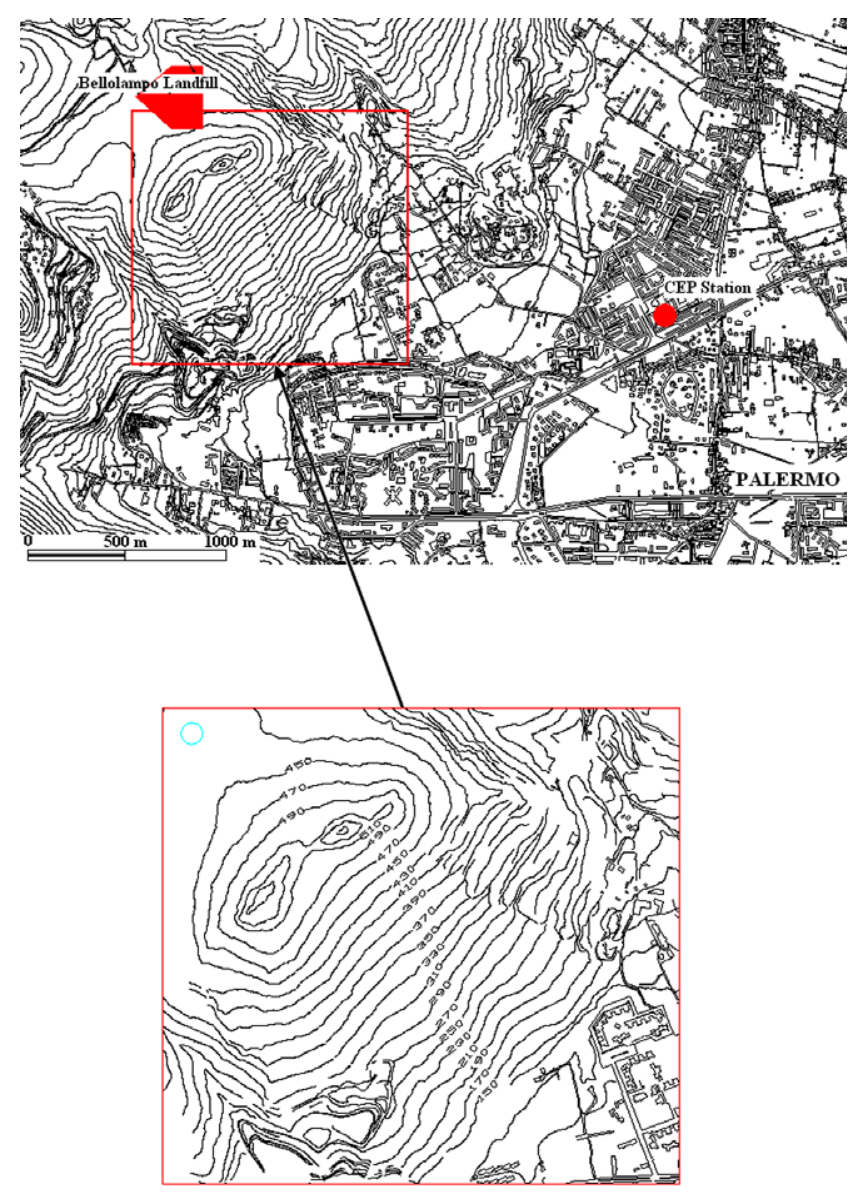

Fig. 1. Position of the Bellolampo landfill and the CEP station (Palermo, Italy).

lampo landfill for the period under study. The company also furnished the electric power data obtained by the recovered biogas for the period January-July 2006.

\section{Landfill schematization as a single point and multiple point source}

In sites close to the dumps, episodes of acute pollution are often noticed. Barbaro et al. (in press) analysed the $\mathrm{CH}_{4}$ concentrations, recorded in two monitoring stations located in peripheral areas of Palermo, and highlighted the presence of acute methane phenomena, to be addressed to the Bellolampo landfill. The authors interpreted such high $\mathrm{CH}_{4}$ concentration levels as the effects of a diffusion process, towards the built-up areas, of the biogas emitted by the landfill. Since, these episodes were observed at night time with stable atmospheric conditions, the diffusion process is supposed to be influenced by the breeze blowing from the mountain towards the city (Barbaro et al., in press). In this situation the biogas emitted by the landfill diffuses towards the inhabited areas, keeping close to the ground. In the present work we considered another pollutant monitoring CEP station (see Fig. 1) because the main idea was to evaluate the biogas emission of the Bellolampo landfill starting from measurements not influenced by the urban fabric. The choice was also due to the position of the station (downwind with respect to the landfill) and to the fact that there are no hills or mountains between the landfill and the station itself, which is not the case for the other monitoring stations. In this context, we adopted the Gaussian plume equation to model the diffusion of pollutants from the landfill towards the CEP monitoring station. 


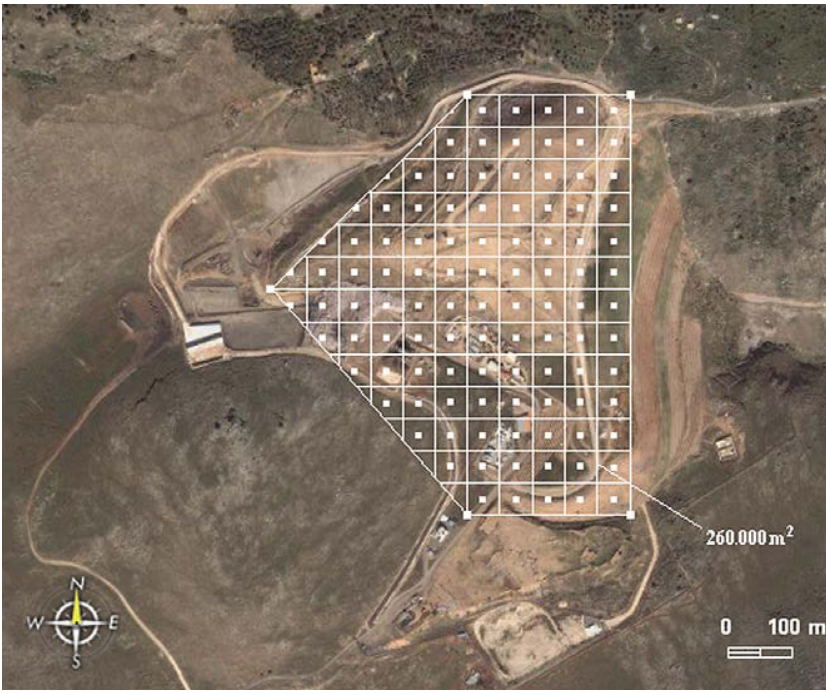

Fig. 2. Schematization of the Bellolampo landfill area (Palermo, Italy).

In relation to the extension of the landfill and to its distance from the observing post, the dump can be schematized as a single point source or a multiple point source. In the following, both schematizations have been considered. The single point source approximation is simpler to adopt and can be used to model pollutant diffusion on large distances between the source and the measurement sites. At sites more close to the landfill, the schematization as a single point source cannot be adopted due to the short distance from it in comparison with its spatial extension. In this case the multiple point source schematization can make the modelling studies more reliable. For the Bellolampo landfill (Fig. 2), the whole area was divided into a set of sub-areas and each of these was considered as a single point source.

The comparison of the results obtained by the application of the two modelling approaches allowed us to make useful considerations to verify the reliability of the single point model in comparison to the multiple point one, which is often closer to real situations.

\section{Mathematic model}

The Eulerian equation (1) governing the transport and the atmospheric diffusion of the pollutants is derived from equations of continuity and motion for a compressible Newtonian fluid applied to an infinitesimal spatial portion (Seinfeld, 1986):

$\frac{\partial \bar{c}}{\partial t}+\bar{u} \frac{\partial \bar{c}}{\partial x}+\bar{v} \frac{\partial \bar{c}}{\partial y}+\bar{w} \frac{\partial \bar{c}}{\partial z}=-\frac{\partial}{\partial x}\left(\overline{u^{\prime} c^{\prime}}\right)-\frac{\partial}{\partial y}\left(\overline{v^{\prime} c^{\prime}}\right)-\frac{\partial}{\partial z}\left(\overline{w^{\prime} c^{\prime}}\right)$

where $u^{\prime}, v^{\prime}$ and $w^{\prime}$ are the fluctuations of the speed components along the axes $x, y$ and $z$, respectively, and $c^{\prime}$ is the fluctuation of the pollutant concentration.

The above equation allows, if no chemical reactions are occurring, to determine the medium concentration of a pollutant species emitted by an instantaneous single point source.

Expressing $\overline{v^{\prime} C^{\prime}}=-K_{y y} \frac{\partial \bar{c}}{\partial y}$ and $\overline{w^{\prime} C^{\prime}}=-K_{z z} \frac{\partial \bar{c}}{\partial z}$, where $K_{i i}$ are the eddy diffusivity coefficients, and assuming that the $x$ axis is in the same direction of a constant wind $\bar{u}$, where $K_{i i}=$ constant, that the diffusive term is negligible with respect to the convective term and that the molecular diffusion term can be neglected when compared to those of the turbulent diffusion, Eq. (1) becomes

$\bar{u} \frac{\partial \bar{c}}{\partial x}=K_{y y} \frac{\partial^{2} \bar{c}}{\partial y^{2}}+K_{z z} \frac{\partial^{2} \bar{c}}{\partial z^{2}}$ which may have the so-called Gaussian plume equation as a possible solution (Pasquill and Smith, 1983):

$\bar{c}=\frac{Q}{2 \pi \bar{u} \sigma_{y} \sigma_{z}} e^{-\frac{y^{2}}{2 \sigma_{y}^{2}}}\left[e^{-\frac{z^{2}}{2 \sigma_{z}^{2}}}\right]$

where $Q$ is the flow rate of the emitted pollutant

$Q=\int_{-\infty}^{\infty} \int_{-\infty}^{\infty} \bar{c}(x, y, z) \bar{u} \mathrm{~d} y \mathrm{~d} z=$ constant

and the quantities $\sigma_{y}$ and $\sigma_{z}$ are representative of the side dimensions of the medium profile of the concentration and are the Gaussian standard deviations on the planes $(x, y)$ and $(y, z)$.

The solution ( 3 ) is valid in an open field and in real cases it is necessary to take into account the reflections of the ground and of the inversion layer (Pasquill and Smith, 1983).

\section{The basic equations for the two schematizations}

The Gaussian pollutant dispersion model (3) has been applied for schematizations both as a single point source and as a multiple point source.

Under the hypothesis that all the diffused materials are inert, almost weightless, and that they do not deposit on the ground but are reflected into the atmosphere, Eq. (3) becomes

$c(x, y, z)=\frac{Q}{\pi \sigma_{y} \sigma_{z} \bar{u}} e^{-\frac{y^{2}}{2 \sigma_{y}^{2}}}\left[e^{-\frac{z^{2}}{2 \sigma_{z}^{2}}}\right]$

Taking into account that the measurement site is situated on the ground and considering unitary values for $Q$ and the mean wind speed, in the single point source schematization Eq. (5) is reduced to

$c(x, y, 0)=\frac{1}{\pi \sigma_{y} \sigma_{z}} e^{-\frac{y^{2}}{2 \sigma_{y}^{2}}}$

For the multiple source schematization, the Gaussian model was applied to each sub-area of the source. A constant emission was assumed for each single cell obtained by dividing the total emission of the landfill by the number of cells that constitute the multiple source.

Considering a generic cell I on the grid (see Fig. 3) with barycentre coordinates $\left(x_{I}, y_{I}\right)$, the recorded concentration in an investigation point $\mathrm{S}$ with coordinates $\left(x_{\mathrm{S}}, y_{\mathrm{S}}\right)$ due to the Ith cell is:

$c\left(x_{\mathrm{S}}, y_{\mathrm{S}}, 0\right)_{I}=\frac{1}{N} \frac{1}{\pi \sigma_{y_{I}} \sigma_{z_{I}}} e^{-\frac{y_{S_{I}}^{2}}{2 \sigma_{y_{I}}^{2}}}$

In Fig. 3 the barycentre of the landfill area is $G$, the direction of the line $I S^{\prime}$ is equal to the wind speed direction, the line $S^{\prime}$ is perpendicular to IS' and $\varphi$ is the angle between the wind speed direction and the line connecting the investigation point $\mathrm{S}$ with the barycentre G.

The total concentration in S due to all the cells is

$c\left(x_{\mathrm{S}}, y_{\mathrm{S}}, 0\right)=\frac{1}{N} \sum_{I=0}^{N} \frac{1}{\pi \sigma_{y_{I}} \sigma_{z_{I}}} e^{-\frac{y_{S_{I}}^{2}}{2 \sigma_{y_{I}}^{2}}}$

The concentrations were calculated for the different values of the distance $\overline{\mathrm{SG}}$ and for several values of the angle $\varphi$.

\section{Results}

\subsection{Analysis of methane and meteorological time series}

From the analysis of $\mathrm{CH}_{4}$ time series recorded at the CEP station, the mean methane concentration was estimated to be $2 \mathrm{ppm}$, re- 


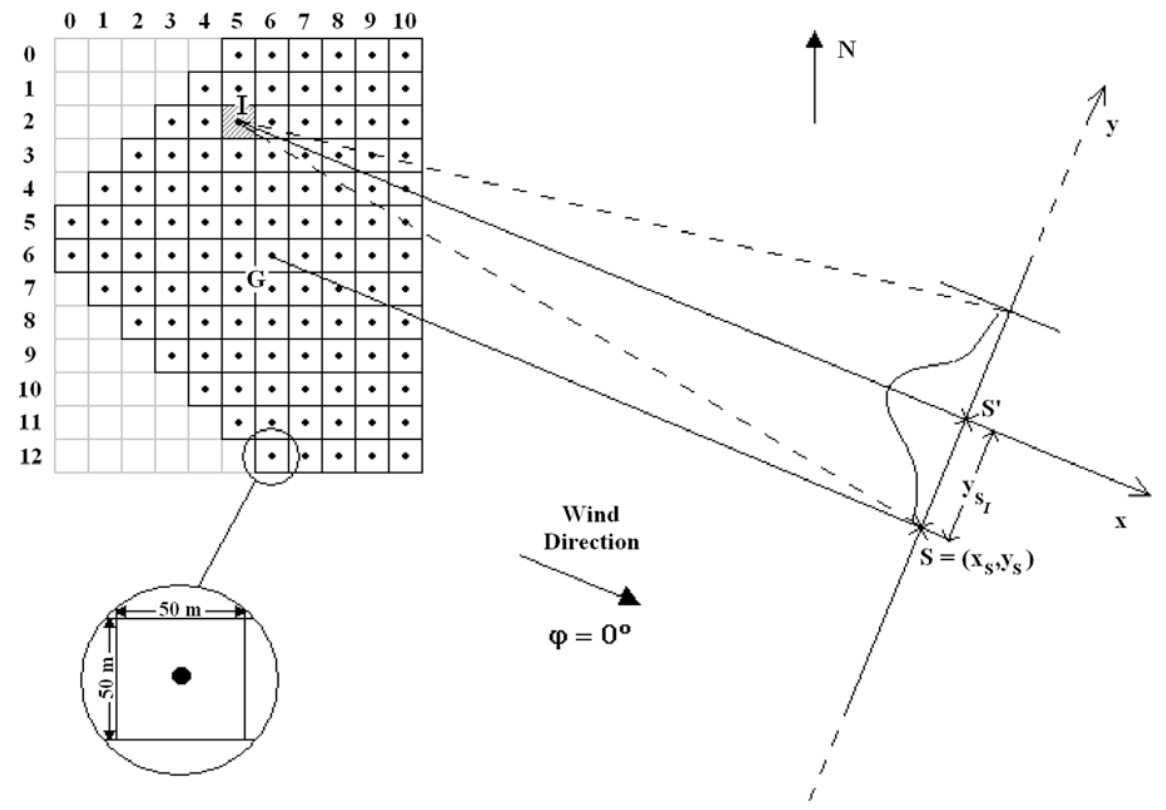

Fig. 3. Definition sketch for the Bellolampo landfill source.
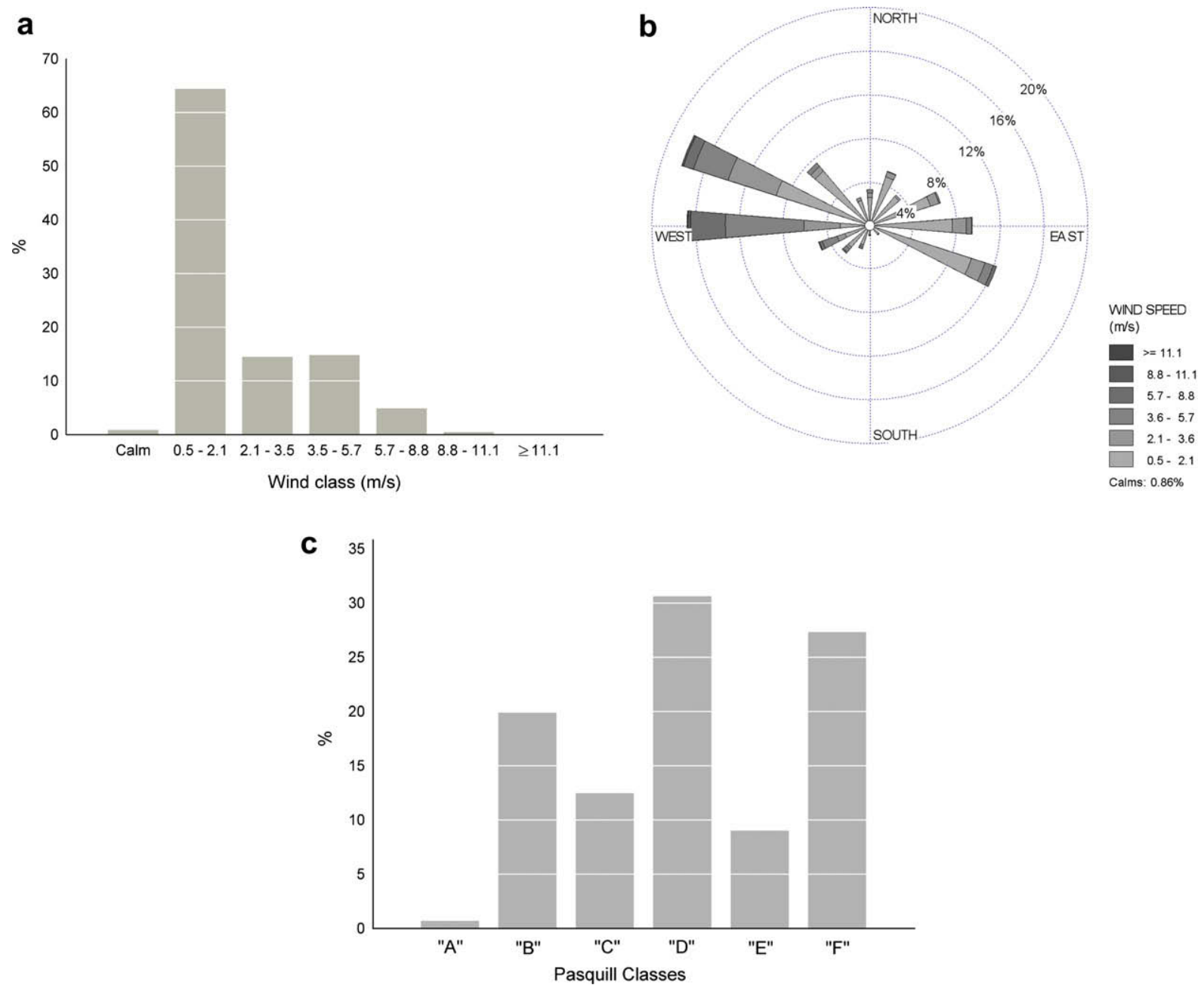

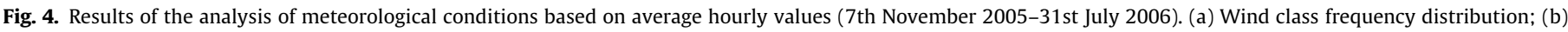
wind direction; (c) Pasquill stability classes' frequency distribution. 
corded on days characterised by a wind speed higher than $2 \mathrm{~m} / \mathrm{s}$ or on days with low wind speed and wind direction very different from the SG direction (Fig. 3). In the study period (267 days) the methane concentration was above $2.5 \mathrm{ppm}$ on 178 days (67\% of the observed period). On $61 \%$ of the days with high methane concentration, it was above $5 \mathrm{ppm}$, while for $10 \%$ of the cases it reached the $10 \mathrm{ppm}$ level. The occurrence of acute phenomena of gas concentration in the inhabited CEP district is to be addressed to the presence of the Bellolampo landfill since no other $\mathrm{CH}_{4}$ source, able to cause such high concentrations, is present in the neighbouring areas.

The results of the analysis of wind speed and direction data are shown in Fig. 4a and b. In the study period the most frequent wind class $(64.4 \%$ ) has a $0.5-2.1 \mathrm{~m} / \mathrm{s}$ range and corresponds to the breeze regime of the site; higher wind speed were less frequently recorded (total occurrence about 35\%). The prevailing wind directions (W and WNW; Fig. 4b) are driven by the topography. To the north of the landfill area, a relatively high mountain (about $700 \mathrm{~m}$ ) acts as a flow barrier.

During daylight hours the stability ranges, as expected, between unstable and neutral conditions. At night time the stability class F is the most frequent (27\%) but, on an annual basis, the frequency of stable atmospheric conditions is 30\% (Cagnetti et al., 1968). Fig. 4c shows the cumulative (day and night) Pasquill stability classes' frequency distribution. The time series of $\mathrm{CH}_{4}$ and wind speed and direction were examined in order to estimate the occurrence of the acute phenomena of methane in relation to wind characteristics. Table 1 summarizes the results of such an analysis. For 142 out of the 178 days, characterised by high methane concentrations, the wind speed was lower than $2 \mathrm{~m} / \mathrm{s}$, or higher than $2 \mathrm{~m} / \mathrm{s}$ with direction in the Bellolampo-CEP angle ( $294 \pm 5^{\circ}$ referred to north). This high frequency of occurrence (about $80 \%$ of the recorded methane acute phenomena) singles out the importance of the wind in causing high methane concentrations at the CEP station in relation to the Bellolampo landfill emissions. The remaining $20 \%$ of cases, out of the Bellolampo-CEP angle, may be explained by the complex topography of the terrain around the landfill site.

\subsection{Comparison of the two methods}

The results of the application of the model in the configurations described above are shown in Figs. 5 and 6.

The graph in Fig. 5 presents the concentration values vs. the landfill distance for deviations $\varphi$ in the range $\left(-20^{\circ}\right.$ to $\left.20^{\circ}\right)$ for the single point source schematization. The concentration differences (referred to deviation $\varphi=0^{\circ}$ ) near the source, as expected for this schematization, increase with increasing angle, while for increasing distances from the source all the curves tend to concentration zero. For distances in the order of the Bellolampo landfill mean radius (about $700 \mathrm{~m}$ ), the concentration values, calculated for the various $\varphi$, differ appreciably, while at $3 \mathrm{~km}$ from the source the concentration in the centre of the plume reduces to about $5 \%$ of the initial value.

Table 1

Occurrence of high methane concentration in the CEP station in relation to wind speed and direction

\begin{tabular}{llll}
\hline $\begin{array}{l}\mathrm{CH}_{4} \text { concentration } \\
(\mathrm{ppm})\end{array}$ & Days & $\begin{array}{l}\text { Wind speed } \\
(\mathrm{m} / \mathrm{s})\end{array}$ & Wind direction \\
\hline$>2.5$ & 94 & $<2$ & \\
& 48 & $>2$ & In the angle Bellolampo-CEP \\
& 36 & $>2$ & Out of the angle Bellolampo-CEP \\
$\leqslant 2.5$ & 89 & & \\
Total number of days & 267 & & \\
\hline
\end{tabular}

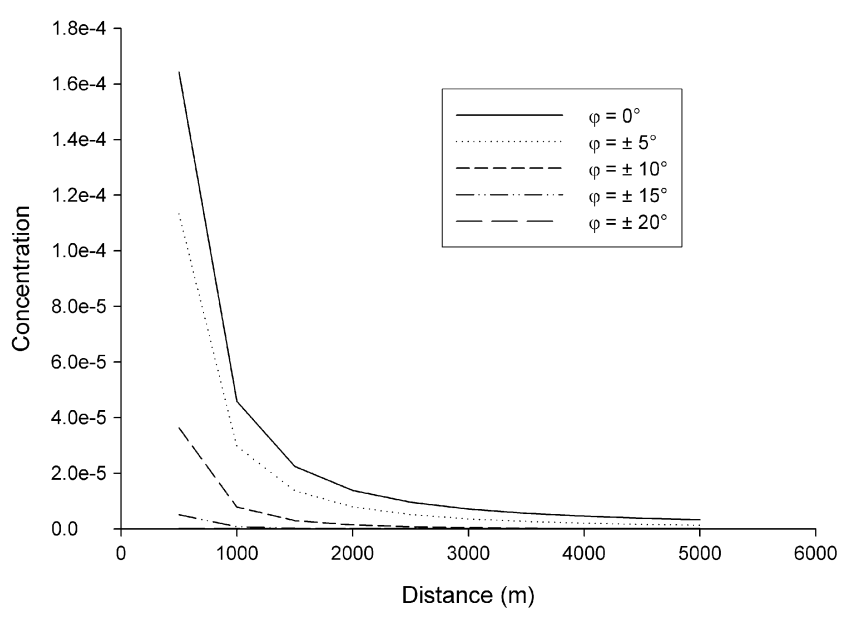

Fig. 5. Pollutant concentration for a single point source schematization.
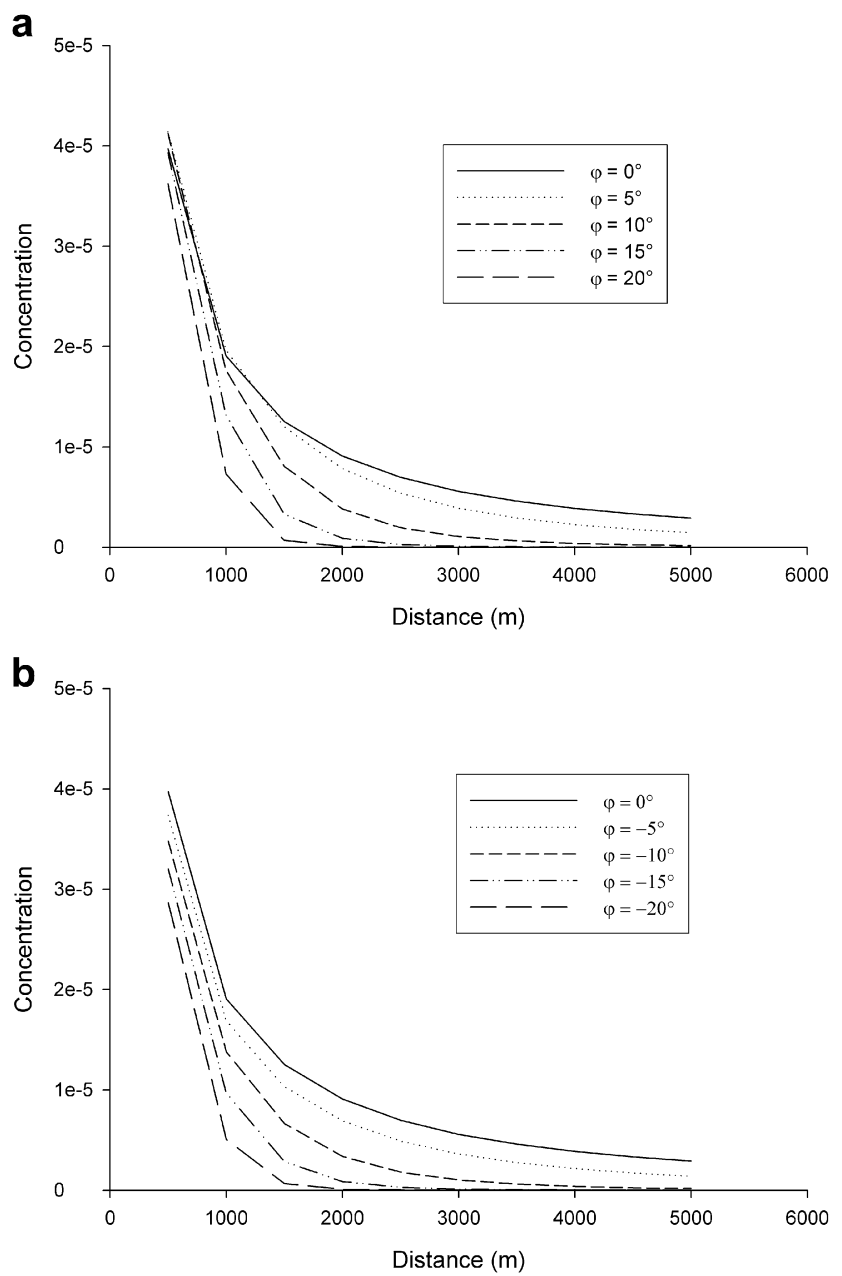

Fig. 6. Pollutant concentration for the multiple point source schematization. (a) $\varphi \geqslant 0^{\circ}$; (b) $\varphi \leqslant 0^{\circ}$.

For the schematization of the landfill as a multiple point source, in Fig. 6a the concentration values vs. the landfill distance for deviations $\varphi$ in the range $\left(0^{\circ}\right.$ to $\left.+20^{\circ}\right)$ are shown, while in Fig. $6 \mathrm{~b}$ the concentration values are evaluated for $\varphi$ in the range $\left(-20^{\circ}\right.$ to $\left.0^{\circ}\right)$.

From the analysis of the curves, it follows that near the source the concentration differences (referred to deviation $\varphi=0^{\circ}$ ), for 


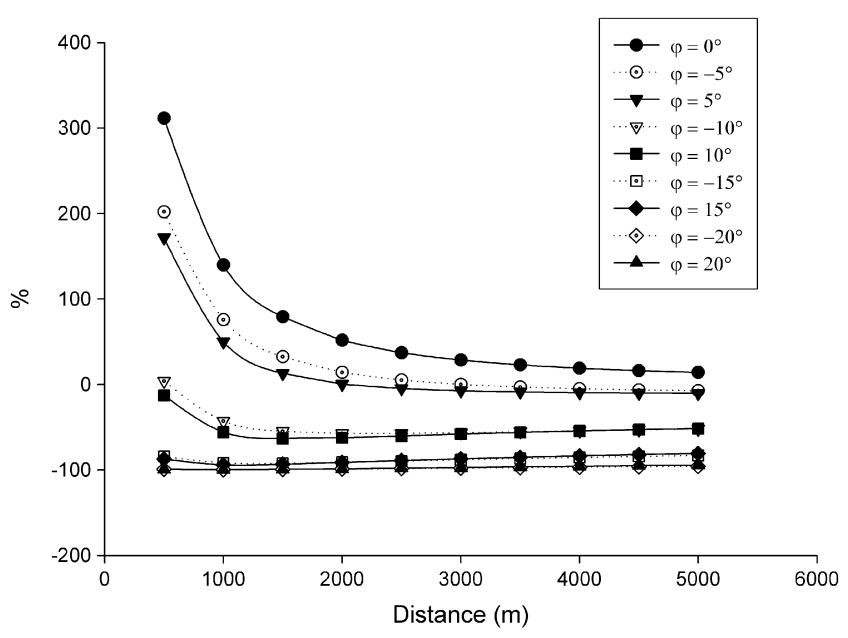

Fig. 7. Percentage differences between the concentrations evaluated with the single point schematization and with the multiple point schematization.

both positive and negative deviation $\varphi$, are small since the total concentration is mainly influenced by closer cells. Furthermore, the maximum concentration at the smallest considered distance (Fig. 6a) is found at the deviations $\varphi=5^{\circ}$ and $\varphi=10^{\circ}$; such result is due to the landfill area asymmetry with respect to the line connecting the barycentre of the dump to the CEP station (line SG in Fig. 3).

The multiple point schematization with the Gaussian plume model foresees that the concentration differences, referred to deviation $\varphi=0^{\circ}$, tend to increase at increasing distance from the source to a certain distance. This is also shown in Fig. 6a and b where the above mentioned distance is about $1500 \mathrm{~m}$ from the dump. For longer distances, all the curves tend to concentration zero.

In order to compare the results obtained by the two schematizations, Fig. 7 shows the percentage differences calculated by

$\frac{\left(c_{\mathrm{S}}-c_{\mathrm{M}}\right)}{c_{\mathrm{M}}} \cdot 100$

as a function of the distance between the investigation site $S$ and the barycentre $\mathrm{G}$ for the different values of $\varphi\left(-20^{\circ}\right.$ to $\left.20^{\circ}\right)$. In the above formula, $c_{M}$ is the concentration evaluated with the multiple point schematization and $c_{S}$ is the concentration calculated in the single point schematization. From this figure it is also possible to recognize the effects of the asymmetry of the landfill schematization.

For deviation angles (in absolute value) larger than $10^{\circ}$, the single point schematization estimates concentration levels smaller than the multiple point one (lower than 50\%). Since we have hypothesized that this latter schematization is to be considered the most appropriate one to the Bellolampo landfill, the above re- sult suggests not to use the single point schematization for angles more than $10^{\circ}$.

For smaller angles the differences between the two schematizations tend to zero at increasing distances. This consideration makes it possible to adopt, for longer distances from the dump, either the multiple point schematization or the single point schematization. In particular, when $\varphi$ is in the range $\left(-5^{\circ}\right.$ to $\left.+5^{\circ}\right)$, the percentage difference is less than $25 \%$ only if the distance from the landfill is more than $3000 \mathrm{~m}$.

\subsection{Gas emission estimation}

The estimate of gas emitted by the landfill was performed using, as above mentioned, the $\mathrm{CH}_{4}$ concentration recorded at the CEP station. A data selection procedure was carried out taking into account the results of the previous sub-section. In particular, we considered all those episodes in which acute methane phenomena were recorded and $\varphi$ ranged between $-5^{\circ}$ and $+5^{\circ}$. The basic equation that is used for calculating the pollutant concentration in every point of the plume is Eq. (5), in which $\bar{u}$ values are those measured at the dump site.

Under the hypothesis that the measurements are carried out along the prevailing direction of the wind $(y=0)$ and that the measurement station is on ground level $(z=0)$, Eq. (5) becomes

$c(x, 0,0)=\frac{Q}{\pi \sigma_{y} \sigma_{z} \bar{u}}$

and, consequently, the emitted gas quantity $Q(\mathrm{~kg} / \mathrm{s})$ is given by

$Q=\pi \sigma_{y} \sigma_{z} \bar{u} c(x, 0,0)$

The application of Eq. (11) on measured methane concentrations allowed estimation of monthly mean values of the methane released in the atmosphere by the dump $\left(\mathrm{CH}_{4(\mathrm{E})}\right.$ in Table 2). In the above equation, $\sigma_{y}$ and $\sigma_{z}$ have been evaluated taking into account the stability classes, the type of terrain and the distance between source and receptor (Pasquill and Smith, 1983).

With the purpose of evaluating the monthly mean quantity of methane produced by the Bellolampo landfill, the following relationship is used:

$$
\mathrm{CH}_{4(\mathrm{G})}=\mathrm{CH}_{4(\mathrm{C})}+\mathrm{CH}_{4(\mathrm{E})}+\mathrm{CH}_{4(\mathrm{Ox})}
$$

where $\mathrm{CH}_{4(\mathrm{G})}$ is the total quantity of methane produced by the landfill, $\mathrm{CH}_{4(\mathrm{C})}$ is the amount of the recovered methane and $\mathrm{CH}_{4(\mathrm{Ox})}$ is the quantity of oxidized methane (Bogner et al., 1997). This latter value is assumed to be on the order of $10 \%$ of the methane transported through the cover of the landfill (Scharff and Jacobs, 2006).

In this approach we considered the $\mathrm{CH}_{4}$ stored in the landfill as negligible, due to the Bellolampo landfill construction. Both this component and the lateral migration of $\mathrm{CH}_{4}$ are included in the emitted methane.

Table 2

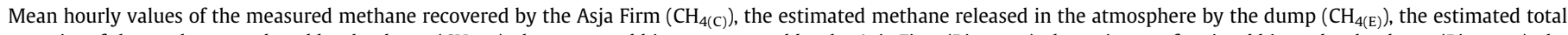

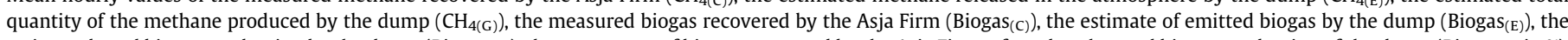

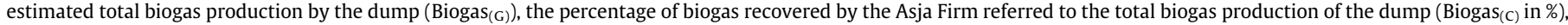
the estimate of methane percentage evaluated by the Asja Firm $\left(\mathrm{CH}_{4}\right.$ in \%) and the estimate of carbon dioxide percentages evaluated by the Asja Firm $\left(\mathrm{CO}_{2}\right.$ in \%)

\begin{tabular}{|c|c|c|c|c|c|c|c|c|c|}
\hline & $\mathrm{CH}_{4(\mathrm{C})}\left(\mathrm{m}^{3} / \mathrm{h}\right)$ & $\mathrm{CH}_{4}(\mathrm{E})\left(\mathrm{m}^{3} / \mathrm{h}\right)$ & $\mathrm{CH}_{4(\mathrm{G})}\left(\mathrm{m}^{3} / \mathrm{h}\right)$ & $\operatorname{Biogas}_{(C)}\left(m^{3} / h\right)$ & $\operatorname{Biogas}_{(E)}\left(m^{3} / h\right)$ & $\operatorname{Biogas}_{(G)}\left(m^{3} / h\right)$ & $\operatorname{Biogas}_{(\mathrm{C})}(\%)$ & $\mathrm{CH}_{4}(\%)$ & $\mathrm{CO}_{2}(\%)$ \\
\hline Nov-05 & 1070.77 & 2890.32 & 4250.12 & 2185.25 & 5898.60 & 8673.71 & 25.19 & 49.0 & 35.0 \\
\hline Dec-05 & 1161.54 & 2997.64 & 4458.94 & 2370.48 & 6117.64 & 9099.89 & 26.05 & 49.0 & 35.0 \\
\hline Jan-06 & 1255.57 & 3249.34 & 4829.85 & 2588.80 & 6699.68 & 9958.45 & 26.00 & 48.5 & 35.8 \\
\hline Feb-06 & 1562.28 & 3056.59 & 4924.53 & 3221.20 & 6302.25 & $10,153.7$ & 31.72 & 48.5 & 35.8 \\
\hline Mar-06 & 1654.81 & 1988.50 & 3842.17 & 3476.50 & 4177.52 & 8071.78 & 43.07 & 47.6 & 37.0 \\
\hline Apr-06 & 1579.89 & 2026.55 & 3809.09 & 3271.00 & 4195.75 & 7886.32 & 41.48 & 48.3 & 35.1 \\
\hline May-06 & 1489.93 & 2108.56 & 3809.35 & 3136.70 & 4439.08 & 8019.69 & 39.11 & 47.5 & 34.4 \\
\hline Jun-06 & 1474.05 & 1838.85 & 3496.79 & 3170.00 & 3954.52 & 7519.97 & 42.15 & 46.5 & 37.0 \\
\hline Jul-06 & 1294.05 & 2164.20 & 3674.67 & 2782.90 & 4654.20 & 7902.52 & 35.22 & 46.5 & 36.8 \\
\hline
\end{tabular}


Table 3

Sold electric energy (available data from the Asja Firm) and estimate of potentially lost electric energy

\begin{tabular}{lll}
\hline & Sold electric energy $(\mathrm{kWh})$ & Lost electric energy $(\mathrm{kWh})$ \\
\hline Jan-06 & 3753.81 & 9714.66 \\
Feb-06 & 4997.31 & 9777.21 \\
Mar-06 & 5092.56 & 6119.46 \\
Apr-06 & 4713.75 & 6046.38 \\
May-06 & 4367.62 & 6181.09 \\
Jun-06 & 4213.72 & 5256.53 \\
Jul-06 & 3835.32 & 6414.30 \\
Mean value & 4304.25 & 6760.65 \\
\hline
\end{tabular}

In Table 2, hourly mean values of the methane $\left(\mathrm{CH}_{4(\mathrm{C})}\right)$ and biogas $\left(\right.$ Biogas $\left._{(\mathrm{C})}\right)$ recovered by the Asja company for the period November 2005-July 2006 are reported. Besides recovering the biogas, the company routinely performs chemical analysis of the biogas in order to estimate the percentages of methane and carbon dioxide $\left(\mathrm{CH}_{4}\right.$ in \% and $\mathrm{CO}_{2}$ in \% in Table 2$)$. Such percentages have been used to estimate both the emitted biogas (Biogas $(\mathrm{E})$ ) and the total biogas production (Biogas $(\mathrm{G})$ ) at the Bellolampo landfill (see Table 2).

Table 3 shows both the power obtained by the recovery plant and the power potentially available using the biogas fraction which escapes into the atmosphere. This last column was evaluated by considering the generated electric power proportional to the amount of biogas conferred to the plant.

\section{Discussion and conclusions}

It is not easy to define the general rules for air flows above uneven terrain; it is possible to affirm that every site is unique since its own characteristics induce specific perturbations on the air flow. As far as the site of the Bellolampo landfill is concerned, Barbaro et al. (in press) have underlined the influence of orography on the prevailing directions of the wind. In the present work, the analysis of wind speed and direction confirmed this influence.

The occurrence of acute phenomena of gas concentration in the inhabited CEP district was observed at night time for days characterised by stable atmospheric conditions. The only source able to cause such episodes was recognized to be the Bellolampo landfill.

The orography of the studied site and the time of occurrence of the acute phenomena induced the assertion that the weak winds observed during such situations are mainly katabatic. During the night the surfaces of the valleys cool down due to the emission of long wave radiations and the lower layers of the air slip down, influenced by gravity.

Typically, these katabatic winds slowly flow down the slopes with a speed around $2-3 \mathrm{~m} / \mathrm{s}$, or with a higher speed in the presence of steeper slants or in the presence of higher differences of temperature (OKE, 2001). In a similar way, the breeze circulation is developed under conditions of an almost clear sky and weak air movement. In fact, in most cases extremely stable atmospheric conditions are present, corresponding to class $\mathrm{F}$ of the Pasquill scale of atmospheric stabilities. The occurrence of such conditions in the Bellolampo landfill site is about 30\% (on an annual basis, see Fig. 4c).

The average monthly estimation of biogas emission into the atmosphere amounts to about $60 \%$ of the total biogas produced by the landfill. This result differs from the one supplied by the Asja company, which is equal to about $50 \%$ of the total gas generation, obtained by using the LandGem software opportunely modified (Asja personal communication). It is important to highlight that the company estimated the biogas emitted by a more recent and wider part of the Bellolampo landfill, where the wells are located (Asja personal communication). There is also a small and abandoned area of the landfill where long-standing refuse has been piled up. Even though this area is not used anymore by the Municipal Company, it continues to release biogas into the atmosphere. This last aspect may contribute to explain the difference of the biogas estimations obtained by our approach and by the approach of the Asja company.

The approach adopted in the present work is to be considered as a first step to estimate the amount of biogas emitted by the landfill. Because the landfill is on top of a hill, the foreseen development will be the use of a more sophisticated dispersion model to account for topography and drainage. Moreover, the model will have to take into account the different heights of the landfill site and the measurement station. The implementation of a measurements campaign in the landfill site will be indispensable to validate the model.

\section{References}

Barbaro, S., Bonanno, A., Boscia, M.L., Rizzo, G., Aronica, S., in press. The impact of landfills on the air quality of towns - a simple heuristic model for the city of Palermo. International Journal of Environment and Pollution 34 (Special issue on "Air Pollution").

Bogner, J., Meadows, J., Czepiel, P., 1997. Bidirectional fluxes of methane between landfills and the atmosphere. Soil Use and Management 13 (4), 268-277.

Cagnetti, P., Giudici, G., Rosini, E., 1968. Condizioni medie di stabilità nei bassi strati della atmosfera per le stazioni meteorologiche italiane. (Average stability conditions in the lower layer of atmosphere for the Italian meteorological stations). In: Proceedings of the XVII Annual Congress of the Italian Geophysical Association. Report CNEN RT/PROT(70)30.

Czepiel, P.M., Shorter, J.H., Mosher, B., Allwine, E., McManus, J.B., Harriss, R.C., Kolb, C.E., Lamb, B.K., 2003. The influence of atmospheric pressure on landfill methane emissions. Waste Management 23, 593-598.

Gregory, R.G., Attenborough, M.G., Hall, C.D., Deed, C., 2003. The validation and development of an integrated landfill gas risk assessment model GasSim. In: Sardinia Proceedings, Cagliari, Italy.

Hansen, J., 2004. Riscaldamento globale: una bomba da disinnescare. (Global warming: a bomb to be defused). Le Scienze, No. 428, p. 76.

Hensen, A., Scharff, H., 2001. Methane Emission Estimates from Landfills Obtained with Dynamic Plume Measurements. Water Air and Soil Pollution, vol. 1(5-6). Springer Netherlands Publishers. pp. 455-464.

Oke, T.R., 2001. Boundary Layer Climates, second ed. Outledge Taylor \& Francis Group (p. 435).

Oonk, J., Boom, A., 1995. Landfill gas formation, recovery and emissions. NOVEM Programme Energy Generation from Waste and Biomass (EWAB), TNO report R95-203, Apeldoorn, Netherlands.

Pasquill, F., Smith, F.B., 1983. Atmospheric Diffusion, third ed. Ellis Horwood Limited-Publishers, England (p. 437).

Scharff, H., Oonk, J., Hensen, A., 2000. Quantifying landfill gas emissions in the Netherlands - definition study. NOVEM Program Reduction of Other Greenhouse Gases (ROB), Project number 374399/9020, Utrecht, Netherlands. Available from: <http://www.robklimaat.nl/docs/3730040010.pdf>.

Scharff, H., Oonk, J., Vroon, R., Hensen, A., de Visscher, A., Boeckx, P., 2003. A comparison of measurement methods to determine landfill methane emissions. NOVEM Programme Reduction of Other Greenhouse Gases (ROB), Project number 0373-01-01-04-001, Utrecht, Netherlands. Available from: <http:// www.robklimaat.nl/docs/3730040010.pdf>.

Scharff, H., Jacobs, J., 2006. Applying guidance for methane emission estimation for landfills. Waste Management 26, 417-429.

Seinfeld, J.H., 1986. Atmospheric Chemistry and Physics of Air Pollution. Wiley Interscience Publication, John Wiley \& Sons, ISBN 0-471-82857-2 (p. 738).

Viviani, G., Torregrossa, M., 1997. Aerobic co-treatment of urban wastewater and leachate from MSW landfill. In: Proceedings Sardinia'97, Sixth International Landfill Symposium, Cagliari. 